\title{
Research on express service based on improving customer satisfaction
}

\author{
Jiangxue $\mathrm{Di}^{1}$, a , Haolan Liang ${ }^{1}$ \\ ${ }^{1}$ Hubei University of Chinese Medicine, Logistics Department, 430065 Wuhan, China
}

\begin{abstract}
With the rapid development of e-commerce in China, the scale of express delivery industry is also expanding rapidly, while the quality of express delivery service has not been effectively improved, with a high value of number lying in the complaint rate of express delivery industry, which leads to low customer satisfaction. Based on the service quality evaluation model, this paper designs the questionnaire with the help of the Richter scale, also constructs the evaluation index of express service quality based on customer satisfaction, with the analysis of the factors through the use of SPSS 23, this essay finds out the main factors that affect the customer's satisfaction with express service quality,and put forwards corresponding suggestion for improvement.
\end{abstract}

\section{Introduction}

To improve express logistics enterprises' customer satisfaction and service quality has been a hot topic of social discussion, which is also the the inevitable result of consumers' persistent pursuit for higher service quality, due to the rapid development of e-commerce in China in recent years. According to Iresearch net statistics, China's e-commerce market trading scale in 2019 exceeded 30 trillion, an increase of 16.2 percent over the same period last year. With the rapid development of e-commerce market, the scale of express logistics market also shows a sharp grows, but the quality of express delivery service presents a situation that does not match the speed of development, exposing the problem of low service quality in the industry. In 2019, the State Post Office and the provincial (district and municipal) postal administrations handled a total of 535,000 consumer complaints through the "12305" postal industry consumer complaint telephone and complaint website, an increase of 21.4 percent over the previous month, and a 73.0 percent decrease from the same period. last year. The main problems of postal consumers' effective complaints about express delivery service are express delay, short loss and delivery service, which respectively account for $42.5 \%, 21.9 \%$ and $21.5 \%$ of the total effective complaints, and these problems also directly lead to the reduction of customer satisfaction with express service.

At present, scholars from home and abroad and all sectors of society have made relevant research on the satisfaction of express service quality to terminal users. Fornell[1] put forward that the measurement of economic benefits of enterprises can be presented through customer satisfaction, so as to make an overall prediction of the future of enterprises. Yonghwa Parked[2] believe that the

\footnotetext{
a Corresponding author: 791424893@qq.com
}

two important factors affecting express delivery enterprises are accuracy and timeliness. M.Holmlund[3] concentrate on the impact of service quality on customer satisfaction, loyalty and purchase behavior. In evaluating service quality index system construction, Marketing scientist A.Parasuraman[4] and others proposed SERVQUAL model, proposing that the quality of service should be examined from five aspects: Tangible, Reliability, Responsiveness, Assurance and Empathy. The questionnaire should be designed based on those five aspects, the data analysis through interviewee information should be made simultaneously.Zheng Bing[5] and others discussed the factors affecting logistics service quality from seven aspects: Time quality, Goods delivery quality, Personnel communication quality etc. They constructed the SQL evaluation system for customer satisfaction research, which is also now one of the most important models of how to improve the quality of business services, and it is also the main theoretical basis for the construction of the evaluation system in this paper.

\section{Design of questionnaire}

The questionnaire designed in this paper is divided into two parts: the first part is mainly about the basic information of the investigated objects, such as gender, age, monthly average number of online shopping, occupation and so on; the second part mainly designs around the secondary index in the system, the problem mainly adopts the scoring form of the Richter scale, the measurement of customer satisfaction survey part of the measurement index is applied to the 1 5 scale designed by American social psychologist Likert. The main object 
of this survey is the young and middle-aged group with rich experience in online shopping, which contacts more express delivery services and has certain representative.

A total of 410 questionnaires were distributed, of which 200 were paper questionnaires and 210 were electronic questionnaires. At the beginning of the study, 400 questionnaires were recovered, with 6 were removed from missing or singular values, there were 394 valid questionnaires, and the effective recovery rate was $98.5 \%$. The following is the collation and statistics of the basic information of the questionnaire. In terms of the sex ratio, female accounted for 71.1 percent (280) of the survey, while male accounted for 28.9 percent (114). In terms of the age of the respondents, 167 were from 18 to 30 years old, accounting for $42.4 \%$. The respondents aged 30-39 were 212 , accounting for $53.8 \%$. It can be seen that young people constitute the backbone of online shopping, who show a greater demand for express delivery services; Meanwhile, this group may also have higher requirements for express delivery services; With the popularity of online shopping, middle-aged people also gradually join the ranks of express consumption. From the frequency of express delivery, the average number of couriers received per month was $100,25.4 \%$; A total of 168 respondents received an average of 2-3 couriers per month, 42.6 per cent; A total of 69 people were interviewed 4-8 times, 17.5 per cent; A total of 57 people were interviewed over 8 times, $14.5 \%$. Descriptive statistical analysis was used for the survey variables of the questionnaire, and the measured results are shown in table 1. The satisfaction score of variables is between 1.66 and 3.46, and the overall satisfaction score is 2.48 , which reflects that the satisfaction degree of consumers to express delivery service is not high. Among the 11 subattributes, consumers are relatively satisfied with such attributes as unimpeded complaint channels, charging standards and remedial measures, with the score is above 3.00; consumers are less satisfied with the timely update of logistics information, intact packaging, reasonable setting of delivery points, and standard signing and receiving process, and the score value is all below 2.00.

Table 1. Descriptive statistics.

\begin{tabular}{|c|c|c|}
\hline & Average & $\begin{array}{c}\text { Standard } \\
\text { deviation }\end{array}$ \\
\hline $\begin{array}{c}\text { Reasonable distribution } \\
\text { points }\end{array}$ & 2.03 & 1.068 \\
\hline $\begin{array}{c}\text { Timely update of } \\
\text { logistics information }\end{array}$ & 1.66 & .655 \\
\hline Well-packed package & 1.95 & 1.120 \\
\hline No loss or damage & 2.13 & .872 \\
\hline Process of receipt & 2.05 & 1.061 \\
\hline Personal Privacy & 2.11 & .949 \\
\hline Fee Standard & 3.36 & .900 \\
\hline Remedy & 3.13 & .686 \\
\hline Distribution frequency & 2.64 & 1.035 \\
\hline
\end{tabular}

\begin{tabular}{|c|c|c|}
\hline $\begin{array}{c}\text { Open channels for } \\
\text { complaints }\end{array}$ & 3.46 & .771 \\
\hline $\begin{array}{c}\text { Complete supporting } \\
\text { facilities }\end{array}$ & 2.79 & .523 \\
\hline
\end{tabular}

\section{Data analysis}

\subsection{Reliability analysis}

This paper uses statistical analysis software SPSS.23 to analyze the reliability of 394 valid questionnaires recovered. From the analysis results, it can be concluded that the reliability of this questionnaire is 0.784 , the a coefficient is between 0.7 and 0.8 , which indicates that the reliability of the scale is good, and the survey data have a great internal consistency.

\subsection{Formatting the text}

The validity test is to evaluate the validity of the index by measuring the deviation between the estimated value and the target value. Validity analysis is mainly achieved by the KMO test and the Bartlett spherical test. The former is mainly to compare the correlation coefficient between the variables, while the latter mainly tests the correlation degree between the variables. The value of the KMO is $0.746>0.7$, indicating that the validity of the questionnaire has increased after the relevant items are put forward, and the $\mathrm{P}$ value of the spherical degree test is 0.000 , which is far less than 0.05 , indicating that the variables are not independent and suitable for factor analysis consequently.

\subsection{Factor analysis.}

In this paper, based on the applicability test of factor analysis, the principal component analysis method is used to carry out the factors of each dimension of the research variables, as shown in Table 2 below. Communality is considered to be an indicator of the relative importance of the detection factor. In general, the greater the communality is, the greater the degree of dependence of the measurement index on the common factor will be, that is, the more suitable the common factor is to explain the index. When the communality of the research variables is greater than 0.5 , it indicates that the common factor is exactly appropriate to explain these indicators. Combined with the SPSS.23 analysis, the co-degree results of the initial variables are shown in the following table. From the analysis results, it can be concluded that the communality of the measurement index is above 0.5 , which indicates the significance of the initial variables on customer satisfaction.

Table 2. Public factor variance.

\begin{tabular}{|c|c|c|}
\hline & Initial & Extraction \\
\hline Service attitude & 1.000 & .878 \\
\hline
\end{tabular}




\begin{tabular}{|c|c|c|}
\hline $\begin{array}{c}\text { Complete supporting } \\
\text { facilities }\end{array}$ & 1.000 & .886 \\
\hline Personal Privacy & 1.000 & .872 \\
\hline $\begin{array}{c}\text { Standardized process of } \\
\text { receipt }\end{array}$ & 1.000 & .864 \\
\hline $\begin{array}{c}\text { Reasonable distribution } \\
\text { points }\end{array}$ & 1.000 & .867 \\
\hline $\begin{array}{c}\text { Distribution frequency } \\
\text { Fee Standard }\end{array}$ & 1.000 & .880 \\
\hline $\begin{array}{c}\text { Remedy } \\
\text { No loss or damage }\end{array}$ & 1.000 & .839 \\
\hline $\begin{array}{c}\text { Open channels for } \\
\text { complaints }\end{array}$ & 1.000 & .895 \\
\hline \begin{tabular}{c} 
Well-packed package \\
\hline
\end{tabular} & 1.000 & .869 \\
\hline
\end{tabular}

As can be seen from table 3, the cumulative load square ratio of the first three characteristic roots of the correlation coefficient matrix of the variables analyzed by exploratory factors reaches $79.914 \%>50 \%$, indicating that the first three factor variables synthetically contain most of the information expressed by the original data indicators, therefore three common factors can be extracted.

Table 3. General Difference Solution Table.

\begin{tabular}{|c|c|c|}
\hline \multicolumn{3}{|c|}{ Rotation Square and Load } \\
\hline Total & $\begin{array}{c}\text { Variance } \\
(\%)\end{array}$ & $\begin{array}{c}\text { Cumulative } \\
(\%)\end{array}$ \\
\hline 3.208 & 34.167 & 34.167 \\
\hline 3.005 & 25.322 & 59.489 \\
\hline 1.704 & 20.425 & 79.914 \\
\hline
\end{tabular}

Table 4 below is the composition matrix after rotation. The first public factor $\mathrm{F} 1$ is closely related to the charging standard, reasonable setting of delivery points and complete supporting facilities, which reflects the tangible nature of the basic conditions and facilities of express delivery enterprises. Therefore, F1 can be named as "Tangible". The second common factor F2 mainly includes the variable distribution frequency, personal privacy and confidentiality, the service attitude of personnel, and the standard signing and receiving process, which reflects the responsiveness of the services that consumers contact in the links through which they receive goods. Therefore, F2 is named as "Responsiveness". A third common factor F3 and package packaging intact, no loss of damage related to a high degree, reflecting the goods in the transport process is safe and reliable, so the F3 named "Reliability ".The third common factor, F3, has a higher correlation with the intact outer package and no loss or damage, which reflects whether the goods are safe and reliable in the process of transportation. Therefore, F3 is named as "Reliability".

Table 4. Composition matrix a after rotation.

\begin{tabular}{|c|c|c|c|}
\hline & \multicolumn{3}{|c|}{ Composition } \\
\hline & 1 & 2 & 3 \\
\hline Fee Standard & .905 & .111 & \\
\hline $\begin{array}{c}\text { Reasonable } \\
\text { distribution } \\
\text { points } \\
\end{array}$ & .870 & & \\
\hline $\begin{array}{l}\text { Complete } \\
\text { supporting } \\
\text { facilities }\end{array}$ & .845 & .409 & \\
\hline $\begin{array}{l}\text { Distribution } \\
\text { frequency }\end{array}$ & & .205 & \\
\hline $\begin{array}{l}\text { Personal } \\
\text { Privacy }\end{array}$ & & .904 & -.225 \\
\hline $\begin{array}{c}\text { Open } \\
\text { channels for } \\
\text { complaints }\end{array}$ & -.172 & -.866 & \\
\hline $\begin{array}{l}\text { Service } \\
\text { attitude }\end{array}$ & .469 & .754 & -.268 \\
\hline $\begin{array}{l}\text { Well-packed } \\
\text { package }\end{array}$ & & -.373 & .849 \\
\hline $\begin{array}{l}\text { No loss or } \\
\text { damage }\end{array}$ & .128 & .315 & .643 \\
\hline $\begin{array}{c}\text { Standardized } \\
\text { process of } \\
\text { receipt } \\
\end{array}$ & .406 & .475 & -.634 \\
\hline Remedy & & .136 & -.169 \\
\hline $\begin{array}{r}\text { Extractic } \\
\text { Rotation me }\end{array}$ & $\begin{array}{l}\text { thod: } p \\
\text { Caesar }\end{array}$ & $\begin{array}{l}\text { compc } \\
\text { zing } n\end{array}$ & $\begin{array}{l}\text { ysis. } \\
\text { variance }\end{array}$ \\
\hline
\end{tabular}

The factor score coefficient matrix can represent the common factor as the linear combination of the variables it contains which be shown in table 5. It reflects the influence of the change of independent variables on the dependent variables.

Table 5. Component score coefficient matrix.

\begin{tabular}{|c|c|c|c|}
\hline & \multicolumn{3}{|c|}{ Composition } \\
\hline & 1 & 2 & 3 \\
\hline $\begin{array}{c}\text { Fee } \\
\text { X1 }\end{array}$ & .392 & -.118 & .060 \\
\hline $\begin{array}{c}\text { Reasonable } \\
\text { distribution } \\
\text { points } \\
\text { X2 }\end{array}$ & .309 & -.162 & -.089 \\
\hline
\end{tabular}




\begin{tabular}{|c|c|c|c|}
\hline $\begin{array}{l}\text { Complete } \\
\text { supporting } \\
\text { facilities } \\
\text { X3 }\end{array}$ & .302 & .050 & .180 \\
\hline $\begin{array}{c}\text { Privacy } \\
\text { X4 }\end{array}$ & -.143 & .364 & -.002 \\
\hline $\begin{array}{l}\text { Service } \\
\text { attitude } \\
\text { X5 }\end{array}$ & .027 & .210 & -.105 \\
\hline $\begin{array}{l}\text { Standardized } \\
\text { process of } \\
\text { receipt } \\
\text { X6 }\end{array}$ & .112 & .036 & -.309 \\
\hline $\begin{array}{l}\text { Well-packed } \\
\text { package } \\
\text { X7 }\end{array}$ & .145 & -.031 & .623 \\
\hline $\begin{array}{c}\text { No loss or } \\
\text { damage } \\
\text { X8 }\end{array}$ & -.096 & .319 & .451 \\
\hline $\begin{array}{c}\text { Distribution } \\
\text { frequency } \\
\text { X9 }\end{array}$ & .139 & -.028 & -.092 \\
\hline \multicolumn{4}{|c|}{$\begin{array}{c}\text { Extraction method: principal component analysis. } \\
\text { Rotation method: Caesar normalizing maximum variance } \\
\text { method. } \\
\text { Component score. }\end{array}$} \\
\hline
\end{tabular}

For $\mathrm{Xj}(\mathrm{j}=1,2,3, \cdots \cdots, 8,9)$ take the mean value (table 6 variable description statistics) to calculate the F1、F2、F3 value. The average values are as follows: Charging standard (3.36), reasonable distribution points (2.15), complete supporting facilities (1.95); Personal privacy (2.13), service attitude of personnel (2.03), standard signing-in process (2.05); The outer packing is in good condition (2.79), without loss or damage (2.64);Distribution frequency (2.11); The value of F1 is 1.187 , the value of F2 is 0.64 , and the value of F3 is 0.717 .

$F 1=0.392 X 1+0.309 \times 2+0.302 X 3-$

$0.143 X 4+0.027 X 5+0.112 X 6+0.145 X 7-0.096 X 8+0.139 X 9$

$F 2=-0.118 \times 1-$

$0.162 X 2+0.05 X 3+0.364 X 4+0.21 X 5+0.036 X 6$ -

$0.031 \times 7+0.319 \times 8-0.028 \times 9$;

$F 3=0.06 \times 1-0.089 X 2+0.18 X 3-0.002 X 4-0.105 X 5-$ $0.309 \times 6+0.623 X 7+0.451 X 8-0.092 X 9$;

According to the variance percentage of each factor in table 6 below, the weight percentage between customer satisfaction F and F1, F2, F3 can be obtained.

It can be seen from Table 6 that the cumulative contribution rate of the three public factors is $79.914 \%$, and their respective contributions are respectively $34.167 \%$, 25.322\% and 20.425\%. Among such statistics, tangibleness accounts for the highest weight, responsiveness and reliability are the second, and their weights are respectively $0.428,0.316$ and 0.256 .

Table 6. General Difference Solution Table.

\begin{tabular}{|c|c|c|}
\hline F1 & 34.167 & 34.167 \\
\hline F2 & 25.322 & 59.489 \\
\hline F3 & 20.425 & 79.914 \\
\hline
\end{tabular}

$F=0.428 * F 1+0.316^{*} F 2+0.256 \cdot * F 3$

F1 "Tangibility", as the public factor with the largest influence on the satisfaction of express service quality, accounts for $42.8 \%$, which indicates that the convenience and rationality of the establishment of express points and the perfection of supporting facilities can quickly realize the on-time payment of goods and improve the satisfaction of consumers in using logistics services. The weight of common factor F2 is $31.6 \%$, which mainly reflects the user experience of consumers in the goods receiving process. Whether the delivery frequency is timely, whether the merchant can well ensure the privacy and security of the goods, and whether the logistics information can be updated in time will significantly affect customer satisfaction. In addition, consumers believe that whether the packaging is intact, whether the goods are damaged, and whether the service is reliable also affect customer satisfaction, and its weight coefficient is 0.256 .

\section{Suggestions for improving customer satisfaction with logistics service quality}

Through the analysis this paper argues that, in the infrastructure construction of tangibility, express enterprises can use the resources integration, to focus on the express market share, the number of employees, the number of outlets, the distance between outlets and the improvement of facilities and equipment, meanwhile, to optimize the network layout, eliminate the bad influence of the chaotic end network. At the same time, the use of information and automation facilities should be popularized, such as increasing the establishment of intelligent express delivery points, which can minimize the proportion of distribution workers to households, reduce labor intensity, shorten distribution time and improve distribution efficiency. The use of automatic sorting equipment can largely avoid the instability of manual sorting, and the efficiency and accuracy of sorting can be greatly improved, so as to reduce the occurrence of the wrong goods. The application of mechanized loading and unloading equipment has greatly improved the loading and unloading efficiency of the goods, and the packaging with good protective performance can greatly reduce the phenomenon of return and exchange of goods caused by the extrusion and breakage of goods in the process of express delivery, and improve the reliability of express delivery service.

\section{Conclusion}


This paper bases on the service quality evaluation model, designing the questionnaire with the use of the Richter scale, also constructs the evaluation index of express service quality based on customer satisfaction, with the analysis of the factors through the use of SPSS 23, finding out the main factors such as tangible, responsiveness and reliability that affect the customer's satisfaction with express service quality. Regarding to these problems, logistics enterprises can improve the service skills and service attitude of employees by strengthening training, enhancing the response degree of service, and providing better service to customers. Through technical and skills training assessment, logistics enterprises can select industry-matching staff, reduce the possible friction in the contact with customers and learn to communicate effectively. At the same time, the enterprise should standardize the service standard, and should not disclose and misappropriate the relevant information of the sender, the addressee and the express, respect the privacy of others and ensure the security of information. In the existing complaint mechanism, express delivery enterprises should refine and score the operation of collection, transportation and delivery links, set up a set of perfect treatment plan and reasonable compensation measures system, which can be used to guide enterprises to respond to customer complaints, take effective means to deal with them in time, and improve customer satisfaction by improving service level.

\section{References}

1. Fornell C. A National Customer Satisfaction Barometer: The Swedish experience [J].Journal of Marketing, 1992, 56( 1) : 6-21.

2. Park Y, Choi J K, Zhang A, Evaluating competitiveness of air cargo express services[J]. Transportation Research Part E Logistics \& Transportation Review, 2009, 45(2) : 321-334.

3. Holmlund M, Harju T. Consumer perception of eservice quality $[\mathrm{J}]$. Ekonomiska Samfundets Tidskrift, 2010,63 (1):5-12.

4. Parasuraman, A. \& V.A. Zeithaml \& L.L. Berry. A Conceptual Model of Service Quality and Its Implication for Future Research [J].Journal of Marketing, 1985, 49(3):41-50.

5. Jinbing Zheng, Yufang Wang \& Dahai Dong. China's local logistics service quality evaluation index and its empirical test[J]. Management Review, 2007,19(4):49-52 